\title{
Oxidative stress enhances tumorigenicity and stem-like features via the activation of the Wnt/ $\beta$-catenin/MYC/Sox2 axis in ALK- positive anaplastic large-cell lymphoma
}

Chengsheng $\mathrm{Wu}^{1,6}$, Nidhi Gupta $^{1 \dagger}$, Yung-Hsing Huang ${ }^{1 \dagger}$, Hai-Feng Zhang ${ }^{1,4}$, Abdulraheem Alshareef ${ }^{1,5}$, Alexandra Chow ${ }^{1}$ and Raymond Lai ${ }^{1,2,3^{*}}$

\begin{abstract}
Background: The phenomenon that malignant cells can acquire stemness under specific stimuli, encompassed under the concept of cancer cell plasticity, has been well-described in epithelial malignancies. To our knowledge, cancer cell plasticity has not yet been described in hematopoietic cancers. To illustrate and study cancer cell plasticity in hematopoietic cancers, we employed an in-vitro experimental model of ALK-positive anaplastic large-cell lymphoma (ALK+ALCL) that is based on the phenotypic and functional dichotomy of these cells, with cells responsive to a Sox 2 reporter (i.e. RR cells) being significantly more stem-like than those unresponsive to the reporter (i.e. RU cells).

Methods: $\mathrm{H}_{2} \mathrm{O}_{2}$ was employed to trigger oxidative stress. GFP expression and luciferase activity, readouts of the Sox2 reporter activity, were quantified by using flow cytometry and luciferase activity assay, respectively. Doxorubicinresistance and clonogenicity were assessed by using the MTS, methylcellulose colony formation and limiting dilution assays. Western blotting and quantitative PCR were used to assess the expression of various members of the Wnt/ $\beta$ catenin pathway. Pull-down studies using a Sox2 binding consensus sequence were used to assess Sox2-DNA binding. Quercetin and 10074-G5 were used to inhibit $\beta$-catenin and MYC, respectively. siRNA was used to downregulate Sox2.

Results: Under $\mathrm{H}_{2} \mathrm{O}_{2}$-induced oxidative stress, a substantial fraction of $\mathrm{RU}$ cells was found to convert to RR cells, as evidenced by their acquisition of GFP expression and luciferase activity. Compared to the native RU cells, converted RR cells had significantly higher levels of doxorubicin-resistance, clonogenicity and sphere formation. Converted RR cells were characterized by an upregulation of the Wnt/B-catenin/MYC/Sox2 signaling axis, previously found to be the key regulator of the RU/RR dichotomy in ALK+ALCL. Furthermore, Sox2 was found to bind to DNA efficiently in converted RR cells but not RU cells, and this finding correlated with significant elevations of several Sox2 downstream targets such as WNT2B and BCL9. Lastly, inhibition of $\beta$-catenin, MYC or Sox2 in RU cells significantly abrogated the $\mathrm{H}_{2} \mathrm{O}_{2^{-}}$ induced RU/RR conversion.
\end{abstract}

Conclusions: We have demonstrated that cancer cell plasticity exists in ALK+ALCL, a type of hematopoietic cancer. In this cancer type, the Wnt/ $/$-catenin/MYC/Sox2 axis is an important regulator of cancer cell plasticity.

Keywords: Anaplastic large-cell lymphoma, Oxidative stress, Cancer cell plasticity, Intra-tumoral heterogeneity

\footnotetext{
* Correspondence: rlai@ualberta.ca

${ }^{\dagger}$ Equal contributors

${ }^{1}$ Department of Laboratory Medicine and Pathology, University of Alberta,

5142J Katz Group Centre for Pharmacy and Health Research, Edmonton, AB

T6G 1Z2, Canada

${ }^{2}$ Department of Oncology, University of Alberta, Edmonton, AB, Canada

Full list of author information is available at the end of the article
} 


\section{Background}

The biological and clinical significance of intra-tumoral heterogeneity have been increasingly recognized [1]. Some degree of intra-tumoral heterogenicity is believed to be resulted from clonal evolution, a process in which individual cancer cell clones gradually acquire an increasing number of genetic defects and the subsequent selection of cell clones carrying highly aggressive or metastatic phenotype [2]. Intra-tumoral heterogeneity is also likely linked to the concept of cancer stem cells (CSCs), which represent a very small population within the tumors that are capable of self-renewal as well as generation of various elements of the tumors $[1,2]$. In recent years, accumulating evidence has suggested that some of the bulk tumor cells can acquire cancer stemness under certain circumstances or specific stimulations [1-3]. This phenomenon is encompassed under the concept of 'acquired stemness' or cancer cell plasticity [4]. Thus far, cancer cell plasticity has been largely described and studied in epithelial and neurogenic malignancies. For instance, MCF7, an estrogen receptor-positive breast cancer cell line, was found to acquire higher levels of tumorigenic potential and chemoresistance upon oxidative stress [5]. In another study, it was found that hypoxic stress can result in the enrichment of CSCs in gliomas, which can be identified by means of their high CD133 expression [6]. To our knowledge, cancer cell plasticity has not been described in hematologic malignancies.

ALK-positive anaplastic large-cell lymphoma (ALK +ALCL) is a distinct form of T-cell non-Hodgkin lymphoma recognized in the World Health Organization Classification of Hematopoietic Neoplasms [7]. The majority of these tumors are found to carry the characteristic reciprocal chromosomal translocation involving $A L K$ and $N P M$, and the resulted fusion gene product, $N P M-A L K$ [7]. NPM-ALK has been shown to be the key oncogenic driver of ALK+ALCL [8]. A large body of experimental data has suggested that NPM-ALK mediates its oncogenic potential by exerting its constitutively active tyrosine kinase activity on a host of cellular signaling proteins, including those in the JAK/STAT, MAPK/ERK, and PI3K/AKT pathways, resulting in their inappropriate activation [8]. In our prior studies of ALK+ALCL, we had identified two distinct cell subsets in ALK+ALCL based on their differential response to a commercially available Sox2 reporter, which key components consist of the Sox 2 regulatory region 2 (SRR2) as well as two gene reporters (Green Fluorescence Protein, GFP and Firefly luciferase) [9]. Specifically, we found that reporter responsive (RR) cells are significantly more tumorigenic and stem-like than reporter unresponsive (RU) cells. In a recently published manuscript, we also have reported that the Wnt/ $\beta$-catenin/MYC/Sox2 signaling axis is the key regulator of the RU/RR dichotomy in ALK+ALCL, with this axis being substantially more active in RR cells than RU cells [10]. Due to the inclusion of the GFP gene in the Sox2 reporter, RU and RR cells present in ALK +ALCL cell lines can be easily detected and purified by using flow cytometry.

In this study, we found that a fraction of RU cells can convert to RR cells upon oxidative stress, and this conversion was associated with the acquisition of cancer stem-like features. We believe that these observations exemplify cancer cell plasticity in a hematologic malignancy. Our study results also have provided further support that the Wnt/ $\beta$-catenin/MYC/Sox2 axis is the key regulator of cancer stemness in ALK+ALCL.

\section{Methods}

Cell lines and chemicals

Karpas 299, an ALK+ALCL cell lines, was a kind gift from Dr. Marshall Kadin (Boston, MA). SupM2, another ALK+ALCL cell lines, was purchased from Deutsche Sammlung von Mikrooorganismen und Zellkulturen GmbH (DSMZ), Germany (catalog number, ACC 509). Karpas 299 and SupM2 cell lines were grown in RPMI 1640 medium (Invitrogen, Life Technologies, Grand Island, NY) with supplementations of $10 \%$ fetal bovine serum (Invitrogen), 1\% Penicillin/Streptomycin (ThermoFisher Scientific, Burlington, Ontario, Canada) and $2 \mu \mathrm{g} / \mathrm{mL}$ puromycin dihydrochloride (Sigma Aldrich, St Louis, MO) in $5 \% \mathrm{CO}_{2}$ atmosphere at $37{ }^{\circ} \mathrm{C}$. Chemicals used in this study, including hydrogen peroxide $\left(\mathrm{H}_{2} \mathrm{O}_{2}\right)$, doxorubicin, $\mathrm{N}$-acetyl-L-cysteine (NAC), iodonitrotetrazolium chloride, 10074-G5 and quercetin, were purchased from Sigma Aldrich.

\section{Flow cytometric isolation of RU and RR cells}

RU and RR cells derived from SupM2 and Karpas 299 were purified with the use of a flow cytometry cell sorter (Becton Dickinson Biosciences, Franklin Lakes, NJ), and details of the method have been described previously [10].

\section{Luciferase reporter assay and flow cytometry}

The luciferase reporter activity was measured by using the luciferase assay kit (Promega, Madison, WI), and the procedure was in accordance with the manufacturer's protocol. The performance of flow cytometry has been detailed in a previous publication [9]. A software (FCS Express 5) from De Novo Software (Glendale, CA) was used to analyze the generated flow cytometry data.

\section{Trypan blue exclusion and MTS}

Trypan blue exclusion and the MTS were used to quantify the number of viable cells (i.e. cell growth), and details of these assays have been previously described [11]. 


\section{Oxidative stress treatment}

SupM2 or Karpas 299 cells growing in the log phase were seeded into $25 \mathrm{~mL}$ Corning $^{\text {TM }}$ cell culture flask (ThermoFisher Scientific Canada). For the $\mathrm{H}_{2} \mathrm{O}_{2}$ rechallenge experiments, cells were initially treated with two different doses of $\mathrm{H}_{2} \mathrm{O}_{2}$ ( 0.3 or $0.5 \mathrm{mM}$ ) for 3 days. On day 3 , cells were subjected to centrifugation $(50 \mathrm{X} \mathrm{g}$, $10 \mathrm{~min}$, room temperature), washed and cultured in fresh culture medium supplemented with either $0.3 \mathrm{mM}$ or $0.5 \mathrm{mM} \mathrm{H}_{2} \mathrm{O}_{2}$ for two additional days (i.e. day 4 and day 5). At the end of the experiments, we performed luciferase reporter assay and flow cytometry to evaluate the luciferase activity and GFP expression, respectively. For the N-acetyl-L-cysteine (NAC) experiments, RU cells derived from SupM2 were treated with $0.3 \mathrm{mM}$ $\mathrm{H}_{2} \mathrm{O}_{2}$ in the presence of $0-20 \mathrm{mM}$ of NAC for 2 days, and these cells were assessed for their SRR2 reporter activity (i.e. luciferase activity and GFP expression). For the 10074-G5 or quercetin experiments, ALK+ALCL cells were treated with $5 \mu \mathrm{M}$ of $10074-\mathrm{G} 5$ or $50 \mu \mathrm{M}$ of quercetin from day 4 to day 5 ( $24 \mathrm{~h}$ in total).

\section{Short interfering RNA and transfection}

Short interfering RNA (siRNA, SMART pool, Dharmacon, Lafayette, CO) against Sox2 was used to downregulate Sox2. Cells transfected with scrambled siRNA (Dharmacon) were included as the negative controls. BTX Electro Square ECM830 (225 V, 8.5 milliseconds, 3 pulses) was used to transfect siRNA species into ALK +ALCL cells. The efficiency of siRNA knockdown of Sox 2 was assessed by using Western blotting.

\section{RNA extraction, CDNA synthesis, and quantitative reverse transcriptase PCR (qRT-PCR)}

The method has been described previously [10]. Primer sequences used in this study were listed in Table 1.

\section{Western blotting}

Details of the method have been described previously [11]. Antibodies reactive to phosphorylated ALK ${ }^{\mathrm{Y} 1604}$ (catalog \#3341), ALK (D5F3 ${ }^{\circ}$ ), phosphorylated STAT3 ${ }^{\mathrm{Y705}}$ (D3A7), STAT3 (124H6), phosphorylated MYC ${ }^{\mathrm{S} 62}$ (E1J4K), MYC (D84C12), Sox2 (D6D9), and $\beta$-catenin (D10A8) were purchased from Cell Signaling Technology (Danvers, MA). Antibody reactive to $\beta$-actin (sc-130300) was purchased from Santa Cruz (Dallas, TX), and antibody against active $\beta$-catenin (8E7) was from Merck Millipore (Toronto, ON, Canada). Anti-mouse IgG (catalog \#7076) and anti-rabbit IgG (catalog \#7074) were from Cell Signaling. Densitometry data was analyzed using Imag J software (National Institutes of Health, Bethesda, MD), and the values were normalized to those of $\beta$-actin or $\gamma$-tubulin.

\section{SRR2 probe binding assay}

Details of this method have been described previously [10]. The sequence of the SRR2 probe is as follows:

5'AAGAATTTCCCGGGCTCGGGCAGCCATTGTGATGCATATAGGATTATTCACGTGGTAATG-3'.

The underlined sequence is the SRR2 consensus sequence.

\section{Methylcellulose colony formation assay}

The methylcellulose-based media were purchased from the R\&D Systems Inc., (Minneapolis, MN). For each experimental group, we seeded 500 cells in each well, as described previously [11]. After $\sim 10$ days of culture, we employed iodonitrotetrazolium chloride to stain the colonies. Only colonies with $>40$ cells were counted. Triplicate experiments were done. Images of the colonies were acquired using the Alphalmager HP (ThermoFisher Scientific Canada).

\section{Limiting dilution assay}

ALK+ALCL cells, with or without $\mathrm{H}_{2} \mathrm{O}_{2}$ treatment, were seeded in RPMI1640 (Invitrogen) supplemented with 20\% fetal bovine serum (Invitrogen), 1\% penicillin/ streptomycin and $2 \mu \mathrm{g} / \mathrm{mL}$ puromycin dihydrochloride (Sigma Aldrich) in 96-well low adherent plate (Corning). Ten different cell numbers, ranging from 1 to 1000 cells were used. After 7 days of culture, cells were stained with iodonitrotetrazolium chloride (Sigma Aldrich) for 24 to $48 \mathrm{~h}$ and images were acquired by using Alphalmager HP (ThermoFisher Scientific Canada). Cell spheres visible to naked eyes were counted. Triplicate experiments were used.

\section{Statistical analysis}

The generated data in all quantitative assays of this study was presented as mean \pm standard deviation. GraphPad Prism 5 software (La Jolla, CA) was employed for

Table 1 The primer sets for qRT-PCR performed in this study

\begin{tabular}{lll}
\hline Gene & Forward Primers & Reverse Primers \\
\hline BCL9 & 5'-GGCCATACCCCTAAAGCACTC-3' & 5'-CGGAAATACTTCGCTCCTITT-3' \\
CTNNB1 & 5'- AAAGCGGCTGTTAGTCACTGG-3' & 5'- CGAGTCATTGCATACTGTCCAT-3' \\
SOX2 & 5'- GCCGAGTGGAAACTTTTGTCG-3' & 5'- GGCAGCGTGTACTTATCCTTCT-3' \\
WNT2B & 5'- GATCAAGATGGTGCCAACTTC-3' & 5'- CCAAGACACAGTAATCTGGAGAG-3' \\
GAPDH & 5'- GGAGCGAGATCCCTCCAAAAT-3' & 5'- GGCTGTTGTCATACTTCTCATGG-3' \\
\hline
\end{tabular}


statistical analysis. The statistical significance of the differences between two experimental groups of test samples was assessed by using Student's $t$-test. Statistical significance is denoted by $*(p<0.05)$ or $* *(p<0.01)$.

\section{Results}

Oxidative stress induces a conversion from RU to RR cells In two of our recently published studies, we described that subsets of RU cells derived from esophageal squamous cell carcinoma and breast cancer cells can convert to RR cells when they were exposed to relatively low concentrations of $\mathrm{H}_{2} \mathrm{O}_{2}$, an agent known to generate reactive oxygen species (ROS) and induce potent oxidative stress [12, 13]. In this study, we asked if the $\mathrm{H}_{2} \mathrm{O}_{2}$-induced RU/RR conversion also exists in hematopoietic cancers such as ALK+ALCL. Two well-established ALK +ALCL cell lines, SupM2 and Karpas 299, were used. As shown in Fig. 1a, 2 days after $\mathrm{H}_{2} \mathrm{O}_{2}$ treatment (0-1. $0 \mathrm{mM}$ ) of purified RU cells, GFP-positive cells became detectable by flow cytometry, with 55\% 'converted RR' cells at $0.5 \mathrm{mM}$ of $\mathrm{H}_{2} \mathrm{O}_{2}$ for SupM2 and $\sim 20 \%$ 'converted RR' cells at $1 \mathrm{mM}$ of $\mathrm{H}_{2} \mathrm{O}_{2}$ for Karpas 299 .

Since high doses of $\mathrm{H}_{2} \mathrm{O}_{2}$ are cytotoxic, we attempted to determine an optimal dose of $\mathrm{H}_{2} \mathrm{O}_{2}$ at which we can generate the highest number of viable converted RR cells for our studies. As shown in Additional file 1: Figure S1, we found this optimal $\mathrm{H}_{2} \mathrm{O}_{2}$ level to be $0.3 \mathrm{mM}$ for SupM2, with which we generated $\sim 30$ viable converted $\mathrm{RR}$ on day 2 , for $\sim 70 \mathrm{RU}$ cells used at the beginning of the experiment. For Karpas 299, this optimal dose was determined to be $0.5 \mathrm{mM} \mathrm{H}_{2} \mathrm{O}_{2}$, with which we generated $\sim 40$ viable converted RR cells on day 2 , for $\sim 100$ RU cells used at the beginning of the experiment. To further increase the yield, we re-challenged ALK+ALCL cells with $\mathrm{H}_{2} \mathrm{O}_{2}$ on day 3 . As shown in Fig. 1b-c, this experimental manipulation resulted in $\sim 60 \%$ GFP-positive, converted RR cells derived from SupM2 and $~ 35 \%$ viable GFP-positive, converted RR cells derived from Karpas 299. This $\mathrm{H}_{2} \mathrm{O}_{2}$ stimulation protocol was used consistently for the remainder of this study. Correlating with these flow cytometry results, the luciferase activity in converted RR cells was significantly higher than that of native RU cells derived from both cell lines (Fig. 1d). Of note, native RR cells derived from SupM2 also showed significantly higher reporter activity (i.e. luciferase and GFP expression) upon $\mathrm{H}_{2} \mathrm{O}_{2}$ stimulation (Fig. 1d-e).

To confirm that the RU to RR conversion induced by $\mathrm{H}_{2} \mathrm{O}_{2}$ was directly linked to the cellular response induced by oxidative stress, we examined if the addition of $\mathrm{N}$ acetyl-L-cysteine (NAC), a pharmacologic agent known to minimize cellular oxidative stress [14], can abrogate the conversion. As shown in Additional file 2: Figure S2A-B, in a dose-dependent manner, NAC significantly lowered the number of $\mathrm{H}_{2} \mathrm{O}_{2}$-induced GFP-positive cells as well as luciferase activity.

\section{Converted RR cells are phenotypically similar to native RR cells}

To address the question of whether converted RR cells are phenotypically similar to native RR cells, we compared these two types of cells with respect to chemoresistance, clonogenicity and sphere-forming ability. First, to evaluate chemo-resistance, we subjected native RU and converted RR cells derived from SupM2 to various doses of doxorubicin, a chemotherapy drug commonly used to treat ALK+ALCL patients [7]. As shown in Fig. 2a, we found that converted RR cells exhibited significantly higher resistance to doxorubicin compared to native RU cells. Expectedly, RR cells stimulated with $\mathrm{H}_{2} \mathrm{O}_{2}$ were also significantly more resistant to doxorubicin than native RR cells at $200 \mathrm{ng} / \mathrm{mL}$ of doxorubicin.

Next we compared native RU and converted RR cells with respects to their clonogenicity by employing the methylcellulose colony formation assay. As shown in Fig. 2b, we found that converted RR cells derived from SupM2 formed significantly more colonies than native RU cells $(113 \pm 7$ versus $74 \pm 9, p=0.008)$. This difference was observed even in the presence of doxorubicin. In comparison, when comparing native $R R$ cells and $R R$ cells stimulated with $\mathrm{H}_{2} \mathrm{O}_{2}$, we found that oxidative stress resulted in a significant increase in colony formation, but only in the presence of doxorubicin (Fig. 2b).

We then performed a comparison between native RU cells and converted RR cells regarding their sphere formation ability in a limiting dilution manner. As illustrated in Fig. 2c, we seeded increasing numbers of cells (i.e. 1 to 1000 ) in each of the wells in 96-well plates, and the lowest cell numbers in which colonies were visible by naked eyes were determined for native RU and converted RR cells. For SupM2, we found that a statistically significant difference between native RU and converted RR cells was found in 8 cells seeded in the wells. For Karpas 299, we found that a significant difference between native RU and converted RR cells was at 125 cells seeded in the wells (Additional file 3: Figure S3). We also compared native RR cells and RR cells stimulated with $\mathrm{H}_{2} \mathrm{O}_{2}$; a significant difference was found at 32 cells seeded in the wells for Karpas 299 cells (Fig. 2c and Additional file 3: Figure S3). The same experiment was performed using SupM2; no significant difference was observed.

Lastly, we assessed the growth rates of native RU cells, converted RR cells, native RR cells and RR cells stimulated with $\mathrm{H}_{2} \mathrm{O}_{2}$. As shown in Additional file 4: Figure S4, no significant differences were found. This result strongly argues against that the observed phenotypic differences between native RU and converted RR cells, as well as between native RR cells and $\mathrm{H}_{2} \mathrm{O}_{2}$-stimulated RR cells 


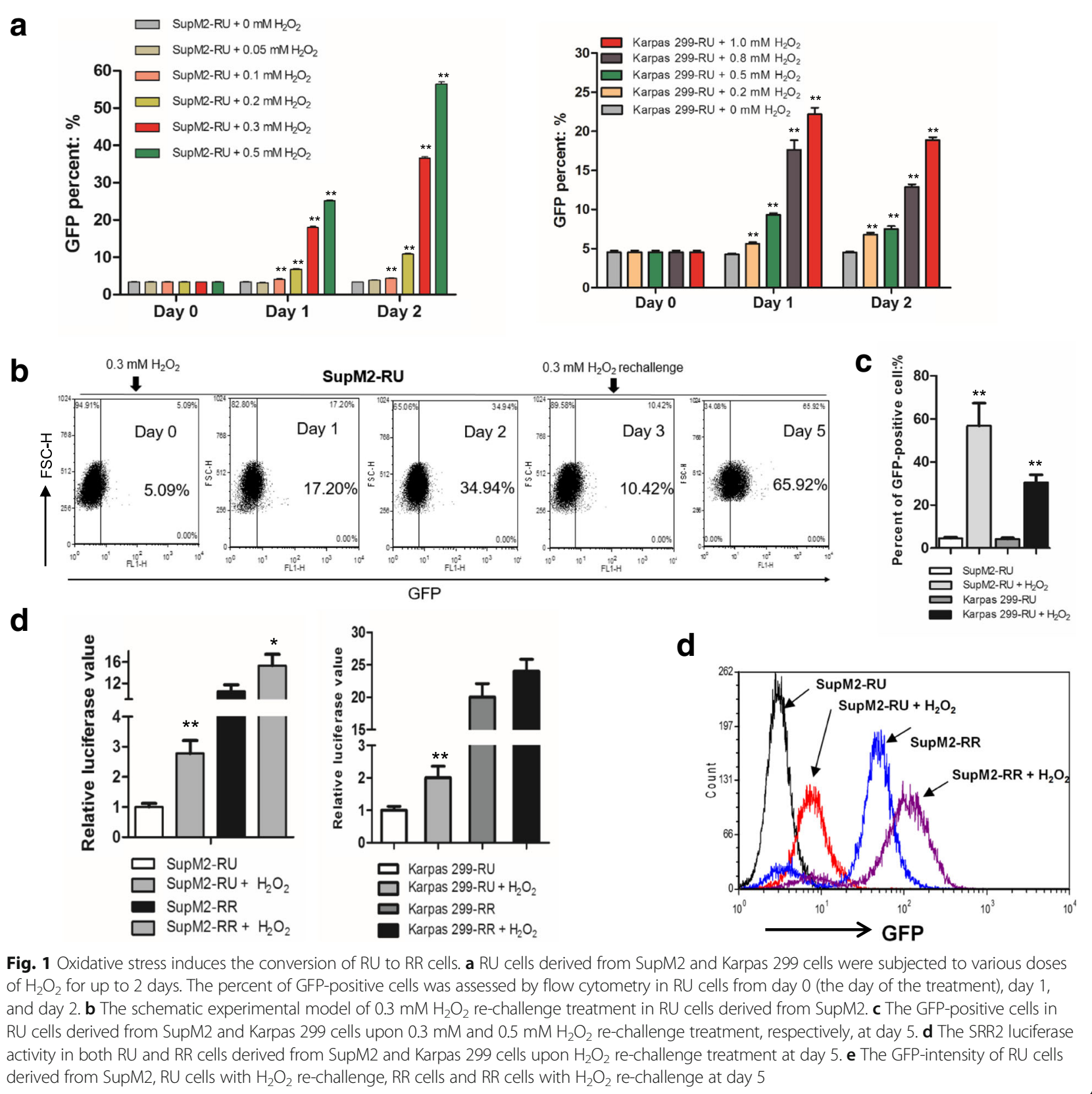

were simply due to a substantial difference in their growth rates.

\section{The Wnt/ß-catenin/MYC/Sox2 axis is active in both converted RR cells and native RR cells}

We recently published that the $\mathrm{Wnt} / \beta$-catenin/MYC/Sox2 axis is a key regulator of the RU/RR dichotomy [10]. Specifically, inhibition of this axis abrogated the RR phenotype and significantly decreased their clonogenicity and stemlike features [10]. In this study, we questioned if the $\mathrm{H}_{2} \mathrm{O}_{2}$ induced RU/RR conversion correlates with an activation of this signaling axis. As shown in Fig. 3a, compared to native
RU cells, converted RR cells derived from SupM2 cells showed higher levels of active $\beta$-catenin, total $\beta$-catenin and $\mathrm{p}-\mathrm{MYC}^{\mathrm{S} 62}$ (the active form of MYC) [15]. The same experiments were repeated using Karpas 299 cells and we found similar findings. In comparison, we did not identify any appreciable differences in the expression and activation of NPM-ALK or STAT3 between native RU and converted RR cells (Additional file 5: Figure S5).

To substantiate our finding that the Sox 2 transcriptional activity was upregulated during the $\mathrm{H}_{2} \mathrm{O}_{2}$-induced RU/RR conversion, we employed quantitative real timePCR (qRT-PCR) to assess the expression of several Sox2 
a

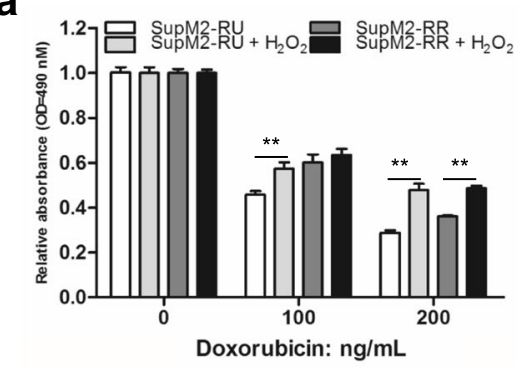

C

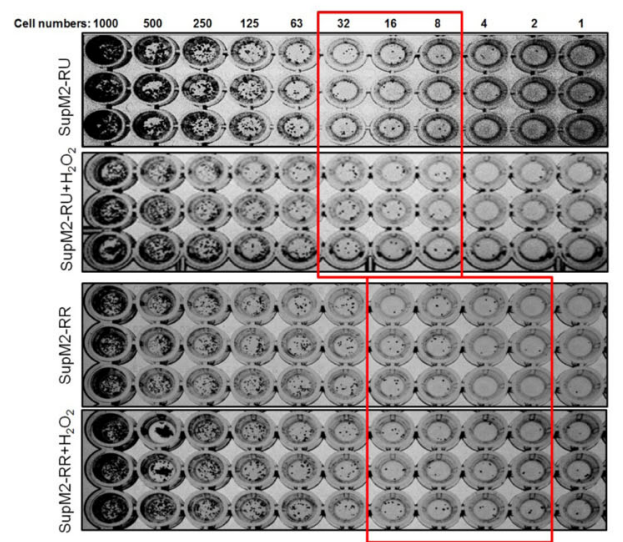

b
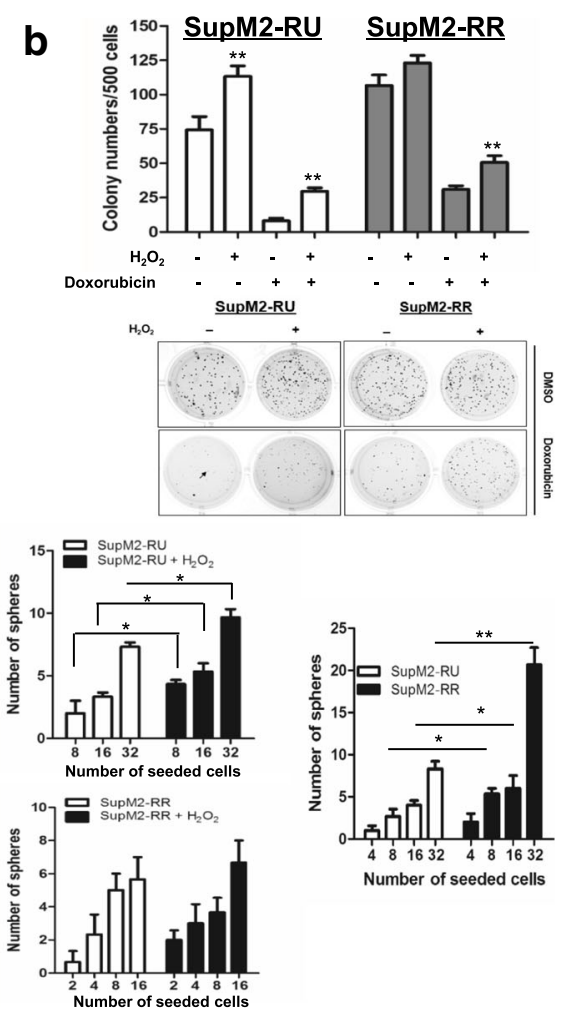

Fig. 2 Converted RR cells share similar biological functions with native RR cells. a RU and RR cells from SupM2 cells were re-challenged with $0.3 \mathrm{mM}$ $\mathrm{H}_{2} \mathrm{O}_{2}$ for 5 days. Then the cells were subjected to $0,100,200 \mathrm{ng} / \mathrm{mL}$ doxorubicin for $48 \mathrm{~h}$. Cells without $\mathrm{H}_{2} \mathrm{O}_{2}$ treatment were included as control. b RU and RR cells derived from SupM2 cells were re-challenged with $0.3 \mathrm{mM} \mathrm{H}_{2} \mathrm{O}_{2}$ for 5 days. Then the cells were processed for methylcellulose colony formation assay in the presence/absence of $50 \mathrm{ng} / \mathrm{mL}$ doxorubicin, cells without $\mathrm{H}_{2} \mathrm{O}_{2}$ treatment were included as control. The graph demonstrated the number of colonies in the above experimental groups. The lower panel showed one representative result of triplicate experiments. Only colony with 40 cells (as pointed by the black arrow) or more was counted. c The serial diluted RU and RR cells derived from SupM2 were seeded in 96-well plate. After $\sim 8$ days, the number of spheres was counted in the highlighted wells circulated by the rectangle lines. The right panel showed the analyzed results which indicated that converted RR cells and native RR cells have formed more spheres in a lower number of cells seeded, in comparison with native RU cells

downstream targets. As shown in Fig. 3b, the mRNA expression levels of $W N T 2 B$ and $B C L 9$ were significantly higher in converted RR cells as compared to native RU cells (Fig. 3b). Similar results were observed when we compared native RR cells with RR cells stimulated with $\mathrm{H}_{2} \mathrm{O}_{2}$ (lower panel in Fig. 3b). Furthermore, we performed the Sox2-SRR2 probe binding assay. As shown Fig. 3c, substantially more Sox 2 protein was pulled down by the biotin-labeled SRR2 probe in converted RR cells as compared to native RU cells. Furthermore, an appreciable increase of Sox2-SRR2 binding was identified in RR cells treated with $\mathrm{H}_{2} \mathrm{O}_{2}$ (Fig. 3c). Notably, the Sox2 protein level in both RU and RR cells derived from SupM2 was not appreciably changed in these experiments (Fig. 3c).

\section{Blockage of Wnt/ $\beta$-catenin/MYC/Sox2 axis abrogates the $\mathrm{RU}$ to RR conversion}

Next, we determined if the inhibition of the Wnt/B-catenin/MYC/Sox2 axis can significantly abrogate the RU/
RR conversion induced by $\mathrm{H}_{2} \mathrm{O}_{2}$. To achieve this goal, we treated RU cells with quercetin (a $\beta$-catenin inhibitor) or 10074-G5 (a MYC inhibitor that can abrogate MYC-MAX heterodimerization and their DNA binding) [16] during the process of $\mathrm{H}_{2} \mathrm{O}_{2}$ challenge, as described in Methods and Materials. As shown in Fig. 4a, pharmacological inhibition of MYC or $\beta$-catenin dramatically decreased the expression level of MYC detectable by Western blots, and significantly reduced the luciferase activity in RU cells stimulated with $\mathrm{H}_{2} \mathrm{O}_{2}$. When we performed siRNA to knockdown Sox2 in RU cells from both ALK+ALCL cell lines, we found a significant decrease in the RU/RR conversion, as evidenced by the finding that the $\mathrm{H}_{2} \mathrm{O}_{2}$-induced increases in the luciferase activity were significantly attenuated (Fig. 4b). In addition, we found that siRNA knockdown of Sox2 in native RU cells derived from SupM2 also largely abrogated the $\mathrm{H}_{2} \mathrm{O}_{2}$-induced chemo-resistance to doxorubicin (Additional file 6: Figure S6). 


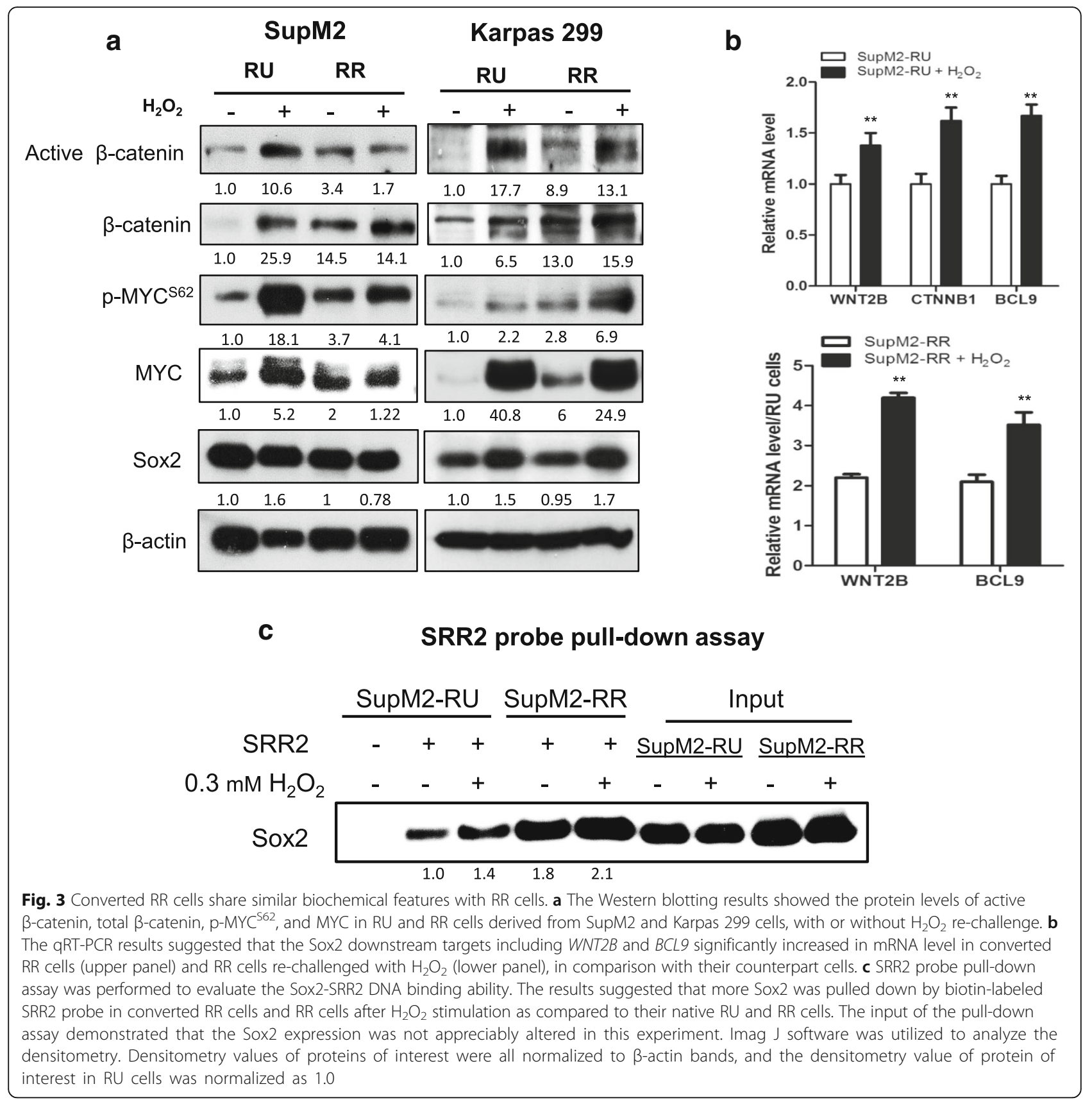

\section{Discussion}

In several recent reviews, the concepts and significance of cancer cell plasticity and acquired cancer stemness have been eloquently explained $[2,17,18]$. One of the key elements of these concepts is that the CSC is a dynamic phenotype, which can be acquired by non-stem cells if appropriate stimuli and microenvironment are provided. Virtually all of the published studies supporting these concepts are based on experimental data derived from malignant epithelial and neural-derived cells, and the induction of cancer stem-like features often involves the use of various chemotherapeutic agents, radiation therapy, hypoxia and oxidative stress $[2,17,19,20]$. For instance, the size of the CSC population in head and neck squamous carcinoma cells, detectable by their $\mathrm{ALDH}^{\text {high }}$ / CD $44^{\text {high }}$ phenotype, was found to be significantly increased when these cells were exposed to cisplatin [21]. In two other studies, human pancreatic cancer cells subjected to a fibrogenic microenvironment were found to acquire CSC-like features [22, 23]. Hypoxia-inducible factors (HIFs), which exists in specific tumor microenvironment niche, is also known to promote metastasis, tumorigenicity and CSC-like features in certain human cancer models $[24,25]$. 


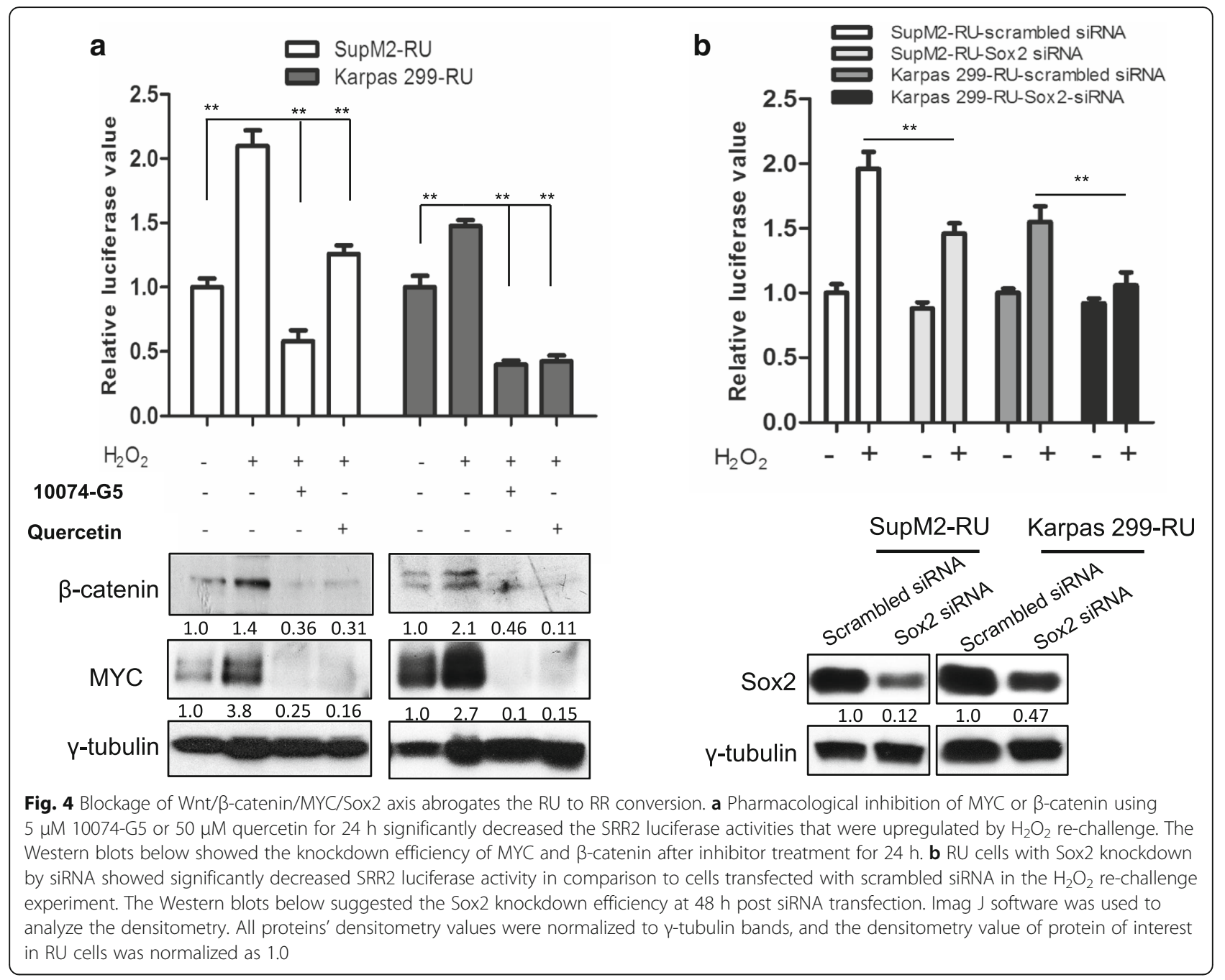

The biochemical basis of how cancer cells acquire stemness is not completely understood, although there is evidence that activation of specific signaling pathways or transcription factors is likely important. In this regard, Saijo et al. have reported that oxidative stress-induced de-differentiation of lung cancer cells into CSCs is mediated via the activation of HOXA5 and upregulation of Sox2 [26]. In another study, hypoxia, which is also an inducer of oxidative stress [27], was found to increase the proportion of CD133-positive CSCs in glioma through the activation of the PI3K/AKT and ERK pathways [6]. A more recent study has shown that the tumorpropagating potential of glioblastoma cells can be enhanced by increasing the expression of a set of transcription factors normally involved in neuronal development, including POU3F2, SOX2, SALL2 and OLIG2 [28]. Epithelial-to-Mesenchymal Transition (EMT), which can be linked to the acquisition of cancer stemness [29, 30], is also known to be regulated by a number of cellular signaling pathways. For instance, activation of the RAS-
MAPK pathway was found to induce EMT and increase the size of the CSC-like cell population [31]. Chaffer et al. have shown that non-CSCs derived from human breast cancers $\left(\mathrm{CD} 44^{\text {low }}\right)$ can convert to CSC's $\left(\mathrm{CD} 44^{\text {high }}\right)$, and this conversion is mediated by ZEB1, an important EMT transcription factor [32]. The same group also demonstrated that TGF $\beta$ collaborates with the canonical and non-canonical Wnt signaling pathways to induce EMT [33].

Studies of acquired cancer stemness require appropriate experimental models. Most of the published studies in this field measured how various experimental manipulations change the size of the CSC populations, which are typically detected based on their expression of specific cell surface markers such as CD133 and CD44 [12, 20, 34-38]. In our studies, we employed a different approach. Specifically, the CSClike population was defined, detected and isolated based on their responsiveness to a Sox 2 reporter. In the literature, we are aware of a number of recent 
publications in which the CSC populations are also identified based on their differential responsiveness to the same Sox2 reporter used in this current study [13, 39-42]. In addition to the Sox2 reporter, we also found one recent publication in which the CSC population from colorectal cancer was identified based on their differential response to a Wnt reporter [38]. Similar to our RU/RR model, Wnt reporter responsive cells were found to be more stem-like than unresponsive cells, and a very small subset of reporter unresponsive cells were found to convert into reporter responsive cells upon stimulation with hepatocyte growth factor [38]. Taken together, we believe that the use of differential reporter responsiveness is a valuable experimental approach to study the acquisition of cancer stemness. In contrast with the use of cell surface markers, we believe that this experimental approach has certain advantages, as it provides direct clues to the biochemical mechanisms regulating the cancer stemness phenotype.

From our literature search, the concept of acquired cancer stemness has not yet been described in hematological malignancies, although a good number of CSC markers for these cancers have been proposed, including CD34+/CD38-/CD90-/interleukin 3 receptor(IL-3R)+/human leukocyte antigen (HLA)-DR/CD117for acute myeloid leukemia (AML), CD34+/CD10-/ CD19-/CD133+ for B-cell precursor acute lymphoblastic leukemia (ALL), and CD34+ for chronic myeloid leukemia (CML) $[43,44]$. Regarding ALK+ALCL, we are aware of a publication in which tumor-propagating cells were identified based on their high Hoechst-efflux ability [45]. These tumor-propagating cells are featured with higher expression levels of NPM-ALK and ATP-binding cassette transporter G2 (ABCG2) as compared to bulk cell populations [45]. However, there was no evidence of a conversion of non-CSCs to CSCs in this study. Overall, we believe that we have demonstrated the first example of cancer cell plasticity in hematopoietic cancers.

We have previously demonstrated the central role of the Wnt/ $\beta$-catenin/MYC/Sox2 axis as the defining feature of RR cells in ALK+ALCL [10]. Specifically, the high level of MYC permits the DNA binding of Sox2, and thus, promotes the transcription of Sox 2 downstream target genes. One of the downstream target genes is WNT2B, which in turn upregulates the Wnt canonical pathway, resulting in an upregulation of MYC [10]. This positive feedback loop exists in RR cells but not RU cells [10]. In support of this model, we found that converted RR cells induced by $\mathrm{H}_{2} \mathrm{O}_{2}$ showed upregulation of this signaling axis. Compared to native RU cells, converted RR cells were found to have a substantially high expression level of Wnt2B, $\beta$-catenin, and MYC, as well as enhanced Sox2-SRR2 binding. In contrast, inhibition of $\beta$ catenin, MYC, or Sox 2 resulted in significantly deceased conversion induced by oxidative stress. Although how exactly oxidative stress stimulates the Wnt/ $\beta$-catenin/ $\mathrm{MYC} / \mathrm{Sox} 2$ axis is not known, redox oxidative species are known to directly activate the Wnt canonical pathway in HEK293 cells by stabilizing $\beta$-catenin and interrupting the interaction between dishevelled (Dvl) and nucleoredoxin (NRX), a strong inhibitor of Wnt/B-catenin signaling [46]. Further studies are required to determine if these mechanisms indeed underlie the RU to RR conversion in ALK+ALCL cells challenged by oxidative stress.

\section{Conclusions}

Our study has demonstrated a novel experimental model in which the acquisition of CSC features can be induced by oxidative stress in ALK+ALCL, a hematologic malignancy. Our results have further substantiated the importance of the Wnt/ $\beta$-catenin/MYC/Sox2 axis in conferring the cancer stem-like phenotype in ALK+ALCL.

\section{Additional files}

Additional file 1: Figure S1. The cell numbers of RU cells derived from SupM2 and Karpas 299 upon various doses of $\mathrm{H}_{2} \mathrm{O}_{2}$ treatment were counted by trypan blue exclusion assay from day 0 to day 3. (PDF $79 \mathrm{~kb}$ )

Additional file 2: Figure S2. Anti-oxidant reagent NAC blocked the increase of GFP-positive cells induced by $\mathrm{H}_{2} \mathrm{O}_{2}$. A-B) Treatment of NAC abrogated the increased GFP-positive cells induced by $0.3 \mathrm{mM} \mathrm{H}_{2} \mathrm{O}_{2}$ for $48 \mathrm{~h}$ in RU cells derived from SupM2 in a NAC-dose dependent manner, read by GFP expression (A) and luciferase activity (B). (PDF $55 \mathrm{~kb}$ )

Additional file 3: Figure S3. The serial dilution experiment in RU and RR cells derived from Karpas 299 cells. The serial diluted RU and RR cells derived from Karpas 299 (from 1000 cells to 1 cell) were seeded in 96well plates. After 8 days, the number of spheres was counted in the highlighted wells circulated by the rectangle lines. The right panel showed the analyzed results which indicated that converted RR cells and native RR cells with $\mathrm{H}_{2} \mathrm{O}_{2}$ stimulation have formed more spheres in a lower number of cells seeded ( 125 cells for RU cells and converted RR cells, 32 cells for RR cells and RR cells with $\mathrm{H}_{2} \mathrm{O}_{2}$ stimulation), as compared with native RU and RR cells, respectively. Note that RR cells also have formed more spheres than RU cells at a lower number of cells seeded (i.e. 32 and 63 cells). (PDF 259 kb)

Additional file 4: Figure S4. The cell growth of $\mathrm{RU}$ and $\mathrm{RR}$ upon $\mathrm{H}_{2} \mathrm{O}_{2}$ re-challenge. A-B) The cell growths of $R U$ and $R R$ cells derived from SupM2 and Karpas 299 after $\mathrm{H}_{2} \mathrm{O}_{2}$ re-challenge, assessed from day 1 (day 6 of $\mathrm{H}_{2} \mathrm{O}_{2}$ re-challenge experiment) to day 3. The results indicated that converted RR cells from both cell lines share similar cell growth rates with native $\mathrm{RU}$ cells, and RR cells after $\mathrm{H}_{2} \mathrm{O}_{2}$ re-challenge also grow in a similar rate with native RR cells. (PDF $103 \mathrm{~kb}$ )

Additional file 5: Figure S5. The activation levels of ALK and STAT3 were inappreciably changed upon $\mathrm{H}_{2} \mathrm{O}_{2}$ re-challenge. The expression levels of pALK ${ }^{\mathrm{Y} 1604}$, ALK, pSTAT3 ${ }^{\mathrm{Y} 705}$, and STAT3 in RU and RR cells with or without $\mathrm{H}_{2} \mathrm{O}_{2}$ re-challenge. The same cell lysates from Fig. 3a were reused in this experiment, and note that the same $\beta$-actin blot as the one in Fig. 3a was recycled for $\mathrm{H}_{2} \mathrm{O}_{2}$-stimulation in $\mathrm{RU}$ and $\mathrm{RR}$ cells derived from Karpas 299 cells. (PDF $102 \mathrm{~kb}$ )

Additional file 6: Figure S6. RU cells derived from SupM2 were transfected with either Sox 2 siRNA or scrambled siRNA which served as a negative control. Cells after siRNA transfection were exposed to $0.3 \mathrm{mM}$ $\mathrm{H}_{2} \mathrm{O}_{2}$ re-challenge. At day 4 of the $\mathrm{H}_{2} \mathrm{O}_{2}$ re-challenge experiment; cells were subjected to $200 \mathrm{ng} / \mathrm{mL}$ doxorubicin for additional $48 \mathrm{~h}$, following by the trypan blue exclusion assay-based cell viability analysis. The 
Western blots in the right panel demonstrated the Sox 2 knockdown efficiency in RU cells from SupM2 $24 \mathrm{~h}$ post transfection. (PDF $48 \mathrm{~kb}$ )

\section{Abbreviations}

ALK+ALCL: ALK-positive anaplastic large-cell lymphoma; CSCs: cancer stem cells; GFP: Green Fluorescence Protein; $\mathrm{H}_{2} \mathrm{O}_{2}$ : hydrogen peroxide; NAC: Nacetyl-L-cysteine; qRT-PCR: quantitative real-time polymerase chain reaction; RR: reporter responsiveness; RU: reporter unresponsiveness; siRNA: short interfering RNA

\section{Acknowledgements}

We thank Jingzhou Huang, the Core Flow Cytometry laboratory at the Department of Experimental Oncology, Cross Cancer Institute, University of Alberta, for his technical favors.

This article has been retrieved and modified from Wu C (2017). Delineation of molecular mechanisms underlying the pathobiology of ALK-positive anaplastic large-cell lymphoma (Doctoral dissertation). Retrieved from https:// era.library.ualberta.ca/files/cmc87pq51z/ Wu_Chengsheng_201702_PhD.pdf.pdf

\section{Funding}

This work was supported by an operating research grant from the Canadian Institute of Health Research awarded to R.L. C.W. was a recipient of the the China Scholarship Council scholarship. H.Z. was a recipient of the Li Ka Shing scholarship. The funding bodies did not play any role in the design of this study, collection/analysis/interpretation of data and the writing of manuscript.

\section{Availability of data and materials}

The data supporting the findings of this study is available from the corresponding author upon reasonable request.

\section{Authors' contributions}

CW and RL designed the experiments. CW performed most of the experiments and participated in data interpretation. CW and RL wrote the manuscript. $N G, Y H, H Z, A A$, and $A C$ performed portions of the experiments, data analysis and intellectual input. NG and $\mathrm{YH}$ contributed equally to this study. All authors read and approved the manuscript.

\section{Ethics approval and consent to participate}

N/A

\section{Consent for publication}

N/A

\section{Competing interests}

The authors declare that they have no competing interests.

\section{Publisher's Note}

Springer Nature remains neutral with regard to jurisdictional claims in published maps and institutional affiliations.

\section{Author details \\ 'Department of Laboratory Medicine and Pathology, University of Alberta, 5142J Katz Group Centre for Pharmacy and Health Research, Edmonton, AB T6G 1Z2, Canada. 'Department of Oncology, University of Alberta, Edmonton, AB, Canada. ${ }^{3}$ DynaLIFEDX Medical Laboratories, Edmonton, AB, Canada. ${ }^{4}$ Department of Pathology and Laboratory Medicine, University of British Columbia, Vancouver, BC, Canada. ${ }^{5}$ Department of Laboratory Medicine and Pathology, Taibah University, Medina, Saudi Arabia. ${ }^{6}$ Current Address: Department of Pathology, University of California San Diego, La Jolla, California, USA.}

Received: 5 May 2017 Accepted: 23 March 2018

Published online: 02 April 2018

\section{References}

1. Meacham CE, Morrison SJ. Tumour heterogeneity and cancer cell plasticity. Nature. 2013;501:328-37.
2. Cabrera MC, Hollingsworth RE, Hurt EM. Cancer stem cell plasticity and tumor hierarchy. World J Stem Cells. 2015;7:27-36.

3. Tang DG. Understanding cancer stem cell heterogeneity and plasticity. Cell Res. 2012;22:457-72.

4. Oren $\mathrm{O}, \mathrm{Smith} \mathrm{BD}$. Eliminating cancer stem cells by targeting embryonic signaling pathways. Stem Cell Rev. 2017;13:17-23.

5. Mahalingaiah PK, Singh KP. Chronic oxidative stress increases growth and tumorigenic potential of MCF-7 breast cancer cells. PLoS One. 2014;9(1):e87371.

6. Soeda A, Park M, Lee D, Mintz A, Androutsellis-Theotokis A, McKay RD, et al. Hypoxia promotes expansion of the CD133-positive glioma stem cells through activation of HIF-1alpha. Oncogene. 2009;28:3949-59.

7. Ferreri AJ, Govi S, Pileri SA, Savage KJ. Anaplastic large cell lymphoma, ALKpositive. Crit Rev Oncol Hematol. 2012;83:293-302.

8. Amin HM, Lai R. Pathobiology of ALK+ anaplastic large-cell lymphoma. Blood. 2007;110:2259-67.

9. Gelebart P, Hegazy SA, Wang P, Bone KM, Anand M, Sharon D, et al. Aberrant expression and biological significance of Sox2, an embryonic stem cell transcriptional factor, in ALK-positive anaplastic large cell lymphoma. Blood Cancer J. 2012;2:e82

10. Wu C, Zhang HF, Gupta N, Alshareef A, Wang Q, Huang YH, et al. A positive feedback loop involving the Wnt/beta-catenin/MYC/Sox2 axis defines a highly tumorigenic cell subpopulation in ALK-positive anaplastic large cell lymphoma. J Hematol Oncol. 2016;9:120.

11. Wu C, Molavi O, Zhang H, Gupta N, Alshareef A, Bone KM, et al. STAT1 is phosphorylated and downregulated by the oncogenic tyrosine kinase NPMALK in ALK-positive anaplastic large-cell lymphoma. Blood. 2015;126:336-45.

12. Gopal K, Gupta N, Zhang H, Alshareef A, Alqahtani H, Bigras G, et al. Oxidative stress induces the acquisition of cancer stem-like phenotype in breast cancer detectable by using a Sox2 regulatory region-2 (SRR2) reporter. Oncotarget. 2016;7:3111-27.

13. Zhang HF, Wu C, Alshareef A, Gupta N, Zhao Q, Xu XE, et al. The PI3K/AKT/ C-MYC axis promotes the acquisition of cancer stem-like features in esophageal squamous cell carcinoma. Stem Cells. 2016:34:2040-51.

14. Reliene R, Fischer $\mathrm{E}$, Schiestl RH. Effect of N-acetyl cysteine on oxidative DNA damage and the frequency of DNA deletions in atm-deficient mice. Cancer Res. 2004;64:5148-53.

15. Marampon F, Ciccarelli C, Zani BM. Down-regulation of c-Myc following MEK/ERK inhibition halts the expression of malignant phenotype in rhabdomyosarcoma and in non muscle-derived human tumors. Mol Cancer. 2006;5:31.

16. Wang H, Chauhan J, Hu A, Pendleton K, Yap JL, Sabato PE, et al. Disruption of Myc-max heterodimerization with improved cell-penetrating analogs of the small molecule 10074-G5. Oncotarget. 2013;4:936-47.

17. Doherty MR, Smigiel JM, Junk DJ, Jackson MW. Cancer stem cell plasticity drives therapeutic resistance. Cancers (Basel). 2016;8(1):E8

18. Chen W, Dong J, Haiech J, Kilhoffer MC, Zeniou M. Cancer stem cell quiescence and plasticity as major challenges in cancer therapy. Stem Cells Int. 2016:2016:1740936.

19. Pisco AO, Huang S. Non-genetic cancer cell plasticity and therapy-induced stemness in tumour relapse: 'What does not kill me strengthens me'. Br J Cancer. 2015;112:1725-32.

20. Ghisolfi L, Keates AC, Hu X, Lee DK, Li CJ. lonizing radiation induces stemness in cancer cells. PLoS One. 2012;7(8):e43628.

21. Nor C, Zhang Z, Warner KA, Bernardi L, Visioli F, Helman الر, et al. Cisplatin induces Bmi-1 and enhances the stem cell fraction in head and neck cancer. Neoplasia. 2014;16:137-46.

22. Hamada S, Masamune A, Takikawa T, Suzuki N, Kikuta K, Hirota M, et al. Pancreatic stellate cells enhance stem cell-like phenotypes in pancreatic cancer cells. Biochem Biophys Res Commun. 2012;421:349-54.

23. Lonardo E, Frias-Aldeguer J, Hermann PC, Heeschen C. Pancreatic stellate cells form a niche for cancer stem cells and promote their self-renewal and invasiveness. Cell Cycle. 2012;11:1282-90.

24. Yang MH, Wu MZ, Chiou SH, Chen PM, Chang SY, Liu CJ, et al. Direct regulation of TWIST by HIF-1alpha promotes metastasis. Nat Cell Biol. 2008;10:295-305.

25. Li Z, Bao S, Wu Q, Wang H, Eyler C, Sathornsumetee S, et al. Hypoxiainducible factors regulate tumorigenic capacity of glioma stem cells. Cancer Cell. 2009:15:501-13.

26. Saijo H, Hirohashi Y, Torigoe T, Horibe R, Takaya A, Murai A, et al. Plasticity of lung cancer stem-like cells is regulated by the transcription factor HOXA5 that is induced by oxidative stress. Oncotarget. 2016;7:50043-56. 
27. Klaunig JE, Kamendulis LM, Hocevar BA. Oxidative stress and oxidative damage in carcinogenesis. Toxicol Pathol. 2010;38:96-109.

28. Suva ML, Rheinbay E, Gillespie SM, Patel AP, Wakimoto H, Rabkin SD, et al. Reconstructing and reprogramming the tumor-propagating potential of glioblastoma stem-like cells. Cell. 2014;157:580-94.

29. Scheel C, Weinberg RA. Cancer stem cells and epithelial-mesenchymal transition: concepts and molecular links. Semin Cancer Biol. 2012;22:396-403.

30. Liu X, Fan D. The epithelial-mesenchymal transition and cancer stem cells: functional and mechanistic links. Curr Pharm Des. 2015;21:1279-91.

31. Morel AP, Lievre M, Thomas C, Hinkal G, Ansieau S, Puisieux A. Generation of breast cancer stem cells through epithelial-mesenchymal transition. PLoS One. 2008:3:e2888

32. Chaffer CL, Marianovic ND, Lee T, Bell G, Kleer CG, Reinhardt F, et al. Poised chromatin at the ZEB1 promoter enables breast cancer cell plasticity and enhances tumorigenicity. Cell. 2013:154:61-74.

33. Scheel C, Eaton EN, Li SH, Chaffer CL, Reinhardt F, Kah KJ, et al. Paracrine and autocrine signals induce and maintain mesenchymal and stem cell states in the breast. Cell. 2011;145:926-40.

34. El Khoury F, Corcos L, Durand S, Simon B, Le Jossic-Corcos C. Acquisition of anticancer drug resistance is partially associated with cancer stemness in human colon cancer cells. Int J Oncol. 2016;49:2558-68.

35. Das B, Tsuchida R, Malkin D, Koren G, Baruchel S, Yeger H. Hypoxia enhances tumor stemness by increasing the invasive and tumorigenic side population fraction. Stem Cells. 2008;26:1818-30.

36. Hu X, Ghisolfi L, Keates AC, Zhang J, Xiang S, Lee DK, et al. Induction of cancer cell stemness by chemotherapy. Cell Cycle. 2012;11:2691-8.

37. Molina JR, Hayashi Y, Stephens C, Georgescu MM. Invasive glioblastoma cells acquire stemness and increased Akt activation. Neoplasia. 2010;12:453-63.

38. Vermeulen L, De Sousa EMF, van der Heijden M, Cameron K, de Jong JH, Borovski T, et al. Wnt activity defines colon cancer stem cells and is regulated by the microenvironment. Nat Cell Biol. 2010;12:468-76.

39. Wu F, Zhang J, Wang P, Ye X, Jung K, Bone KM, et al. Identification of two novel phenotypically distinct breast cancer cell subsets based on Sox2 transcription activity. Cell Signal. 2012;24:1989-98.

40. Liang S, Furuhashi M, Nakane R, Nakazawa S, Goudarzi H, Hamada J, et al. Isolation and characterization of human breast cancer cells with SOX2 promoter activity. Biochem Biophys Res Commun. 2013;437:205-11.

41. Marques-Torrejon MA, Porlan E, Banito A, Gomez-lbarlucea E, LopezContreras AJ, Fernandez-Capetillo O, et al. Cyclin-dependent kinase inhibitor p21 controls adult neural stem cell expansion by regulating Sox2 gene expression. Cell Stem Cell. 2013;12:88-100.

42. Iglesias JM, Leis O, Perez Ruiz E, Gumuzio Barrie J, Garcia-Garcia F, Aduriz A, et al. The activation of the Sox2 RR2 pluripotency transcriptional reporter in human breast Cancer cell lines is dynamic and labels cells with higher tumorigenic potential. Front Oncol. 2014;4:308.

43. Zagozdzon R, Golab J. Cancer stem cells in haematological malignancies. Contemp Oncol (Pozn). 2015;19:A1-6.

44. Graham SM, Jorgensen HG, Allan E, Pearson C, Alcorn MJ, Richmond L, et al. Primitive, quiescent, Philadelphia-positive stem cells from patients with chronic myeloid leukemia are insensitive to STI571 in vitro. Blood. 2002;99:319-25.

45. Moti N, Malcolm T, Hamoudi R, Mian S, Garland G, Hook CE, et al. Anaplastic large cell lymphoma-propagating cells are detectable by side population analysis and possess an expression profile reflective of a primitive origin. Oncogene. 2015;34:1843-52.

46. Funato Y, Michiue T, Asashima M, Miki H. The thioredoxin-related redoxregulating protein nucleoredoxin inhibits Wnt-beta-catenin signalling through dishevelled. Nat Cell Biol. 2006;8:501-8.

\section{Submit your next manuscript to BioMed Central and we will help you at every step:}

- We accept pre-submission inquiries

- Our selector tool helps you to find the most relevant journal

- We provide round the clock customer support

- Convenient online submission

- Thorough peer review

- Inclusion in PubMed and all major indexing services

- Maximum visibility for your research

Submit your manuscript at www.biomedcentral.com/submit
Biomed Central 